\title{
La importancia de las Políticas públicas en el fomento del Turismo Cultural-Religioso en Guanajuato
}

The importance of public policies in promoting Cultural-Religious tourism in Guanajuato

A importância da política pública na promoção do turismo em Guanajuato Cultural religiosa

DOI: http://dx.doi.org/10.23913/ricsh.v6i11.111

Saúl Manuel Albor Guzmán

Campus Celaya-Salvatierra, Universidad de Guanajuato, México saulborsmag@gmail.com

Eva Lozano Montero Campus Celaya-Salvatierra, Universidad de Guanajuato, México monteroe@ugtomx.onmicrosoft.com

Roberto Godínez López Campus Celaya-Salvatierra, Universidad de Guanajuato, México roberto.godinez@gmail.com

\section{Resumen}

El turismo cultural en su aspecto espiritual religioso, tiene la potencialidad de convertirse en factor de desarrollo y competitividad turística tanto nacional como internacional en la Ciudad de Guanajuato y otras ciudades del Bajío. El objetivo de este trabajo es analizar su incidencia en el propio desarrollo regional. El tipo de investigación es cualitativa, aplicándose el método documental, descriptivo y analítico. Se arriba a la conclusión de que este turismo cultural puede ser fomentado mediante políticas públicas adecuadas que den a conocer el patrimonio cultural y contribuir así al desarrollo social y económico de la ciudad de Guanajuato. 
Palabras clave: fomento turístico, patrimonio cultural, políticas públicas, turismo religioso.

\section{Abstract}

Cultural tourism in its spiritual religious aspect, has the potential to become a factor of development and national and international tourist competitiveness in Guanajuato City and other cities of the Bajio region. The objective of this work is to analyze its impact on regional development. It is concluded that this cultural tourism can be promoted through appropriate public policies to give to know the cultural heritage and thus contribute to the social and economic development of Guanajuato City.

Key words: tourism promotion, cultural heritage, public policies, religious tourism.

\section{Resumo}

O turismo cultural em seu aspecto espiritual religiosa, tem o potencial de tornar-se um factor de desenvolvimento e a competitividade nacional e internacional do turismo na cidade de Guanajuato e outras cidades do Bajío. O objetivo deste artigo é analisar o seu impacto sobre o próprio desenvolvimento regional. A pesquisa é qualitativa, aplicando-se o documentário, o método descritivo e analítico. Cabe à conclusão de que este turismo cultural pode ser promovida através de políticas públicas apropriado divulgar o património cultural e contribuir para o desenvolvimento social e económico da cidade de Guanajuato. Palavras-chave: desenvolvimento do turismo, património cultural, política pública, turismo religioso.

Fecha Recepción: Julio 2016 Fecha Aceptación: Enero 2017 


\section{Introducción}

En las últimas décadas, dentro de las políticas públicas, se ha fomentado y puesto de relieve la actividad turística, la llamada "industria sin chimeneas", como una parte importante de la economía y el desarrollo de un país, que presupone una importante movilidad social y de recursos públicos y privados para alentar dicha actividad humana. Los países europeos explotaron en su momento el turismo para impulsar su desarrollo. Tal fue el caso de España, que después de la Guerra Civil y la Segunda Guerra Mundial, como política pública centró su atención en el desarrollo y fomento de esta actividad como un elemento fundamental de su progreso económico. No se diga en Italia, con su gran riqueza cultural, el turismo ha desempeñado el papel transformador de su economía, por señalar algunos ejemplos.

El turismo presupone también encuentros, diálogos, intercambios culturales e idiosincráticos de pueblos enteros, que entran en comunión con la cultura de un pueblo o nación.

México no ha sido la excepción, por su riqueza cultural y geográfica se ha privilegiado cierto tipo de turismo, el comercial de esparcimiento, aprovechando las riquezas paisajísticas, sobre todo de playas y otras bellezas naturales. Se ha continuado con el llamado turismo de negocios, el turismo cultural y, con menos atención, pero cada vez con más interés, lo que se ha denominado turismo espiritual o religioso -formando parte del turismo cultural- (Belmonte, R. A., 2009).

En este sentido, el Estado de Guanajuato es considerado por la propaganda gubernamental, tanto federal, estatal y municipal, como un destino cultural de México, y efectivamente lo es: cuenta la entidad con atractivos culturales prehispánicos como las zonas arqueológicas de las Plazuelas cerca de Pénjamo, la de Peralta entre Irapuato y Abasolo, Cañada de la Virgen entre Guanajuato y San Miguel de Allende, y el Cóporo en la parte norte del Estado hacia San Luis Potosí, no sin tener en cuenta la cultura de Chupícuaro cerca de Acámbaro, zonas arqueológicas mesoamericanas en las que se puede apreciar el aporte de chichimecas y purépechas. 
Asimismo, Guanajuato cuenta con exponentes clásicos de la arquitectura barroca y colonial, que han dejado su impronta por todo el Estado, desde el cristianismo primitivo y protohistórico a lo más granado de lo novohispano, donde el franciscanismo, el agustinismo y los jesuitas dejaron su herencia en piedra.

Desde luego que va tomando auge lo que se ha llamado el turismo de negocios en zonas como León y Celaya, y por supuesto, el turismo histórico y de paisaje, así como el mineral y de ingeniería, como el de sistema de presas y la calle subterránea en la capital del Estado, único en el mundo. Guanajuato cuenta también con paisajes emblemáticos y, dado su enclave geográfico en el centro del país, se encuentra muy bien comunicado por redes carreteras y aeroportuarias.

Sin embargo, el turismo con el que cuenta Guanajuato Capital es un turismo de masas, de paso, lo que comúnmente en el argot popular se le llama "turismo charamusquero", esto por los dulces elaborados en la región, las momias de Guanajuato, fuente principal de ingresos del Ayuntamiento y los "museos" de instrumentos de torturas en los que se explota cierto morbo por el dolor infligido, no sin las consiguientes leyendas populares ahistóricas.

En cuanto al turismo cultural, como parte ya de una política de la Federación se encuentra el Festival Cervantino que cada año se organiza en la capital, con extensiones a León y San Miguel de Allende, que se ha convertido, de igual forma, en un turismo de masas muy coyuntural y dirigido a nichos muy bien identificados.

A pesar de esta riqueza cultural con que cuenta Guanajuato en la capital y en el resto del Estado, que tiene además dos ciudades Patrimonio Cultural de la Humanidad (Guanajuato y San Miguel de Allende), se ha detectado, por ejemplo, un disímil desarrollo turístico en ambas ciudades, el potencial turístico cultural de la Ciudad de Guanajuato puede diversificarse en su oferta turística, la cual podría canalizarse precisamente al aspecto cultural, y en este, al turismo espiritual o religioso, veta todavía sin explotar en todas sus potencialidades.

Desde 1972 se creó, por parte de la Organización de las Naciones Unidas para la Educación, la Ciencia y la Cultura (UNESCO por sus siglas en Inglés), el título de 
Patrimonio de la Humanidad, para bienes y lugares concretos de especial relevancia cultural, desde los bienes materiales a los inmateriales.

Actualmente, dentro de su relación oficial de Bienes del Patrimonio de la Humanidad correspondiente a México, en el vínculo Cultura, se cuenta con los recursos relativos a la lista del patrimonio cultural mundial e inmaterial en el que puede consultarse su relación actualizada y pormenorizada (2016, http://www.unesco.org/new/es/culture/), se incluyen 33 bienes culturales, de los cuales, precisamente, la Ciudad histórica de Guanajuato y minas adyacentes fueron nombrada en 1988, y la Villa Protectora de San Miguel el Grande y Santuario de Jesús Nazareno de Atotonilco fueron designada en 2008.

En Guanajuato existe un compromiso político, incipiente aún, sobre el turismo cultural y espiritual, dicho compromiso es polifacético, dependiendo de las exigencias del momento. La acción política puede desplegarse en el cuidado y conservación de los templos que son parte del Patrimonio cultural y orgullo de la ciudad, se trata de una acción cultural que tiene una importancia fundamental, incluso, algunas empresas podrían estar interesadas.

En estados vecinos como Jalisco, existía por parte del gobierno estatal, la presentación (2016, http://www.jalisco.gob.mx/) de rutas turísticas, ejemplo de ello es la ruta cristera como parte de una política de turismo estatal, un turismo religioso. Por cuestiones de cambio de gobierno, en la actualidad sólo se presentan los atractivos culturales de los diversos municipios.

En Guanajuato a nivel estatal, hace más de cuatro años se tenía un curso que organizaba el Instituto Estatal de Cultura sobre la ruta de los conventos en el Estado, era un diplomado vivo pues se impartía el curso in situ, desde Acámbaro, Salvatierra, Yuriria, Celaya, Guanajuato y San Miguel de Allende, el patrimonio cultural de Guanajuato Capital bastaría para un diplomado al respecto.

El año de 2014, según informes oficiales, el Gobierno del Estado de Guanajuato destinó la suma de 93.1 millones de pesos a la rehabilitación de 18 recintos religiosos a lo largo del Estado (García, J., 2014, Periódico AM), recursos provenientes también de la Federación, de la partida correspondiente al rescate del patrimonio cultural. Las obras son solicitadas normalmente por los párrocos encargados de los templos. 
La problemática consiste en que el Ayuntamiento en Guanajuato no ha implementado suficientes políticas por razones presupuestarias precarias, para hacer de Guanajuato un verdadero destino cultural de México. No obstante que forma ya parte del léxico de las políticas públicas estatales en materia de turismo, ha privilegiado la promoción y explotación del museo de las momias y los paseos artísticos de las estudiantinas. Existen también algunos problemas jurídicos en cuanto a la propiedad de algunos templos que colindan con los espacios públicos que gestionan el Municipio y otras entidades estatales.

Por las joyas y tesoros artísticos que tienen los Templos de Guanajuato y de otras ciudades, su arquitectura sagrada, su semana santa, el repique de sus campanas, sus pinacotecas, son los espacios sagrados en los que la Liturgia católica se manifiesta en todo su esplendor evangelizador y barroquismo sobrio. Desde la música que sale de sus órganos en festivales anuales que se organizan en sus interiores, el pueblo participa del influjo religioso y cultural de la liturgia católica, muy relacionada con el arte en Guanajuato. Parte de la población sólo se interesa por festival Cervantino, que produce cierta derrama económica muy dispar en la ciudad.

\section{Problema de investigación y estado del arte}

El problema de investigación consiste en identificar algunos factores determinantes para impulsar el turismo cultural en Guanajuato, mediante políticas públicas enfocadas al fomento del turismo cultural para llegar a nuevos sectores demandantes de este tipo de turismo. Ante la demanda turística cultural se carece de una guía cultural impresa a la manera de folleto-libro, que pueda ofertar como parte de las políticas públicas en la materia, los principales sitios turísticos culturales de Guanajuato. Sólo existen folletos meramente informativos. Esta guía impresa podría detonar el turismo cultural espiritual en Guanajuato Capital, con proyección a otras ciudades por la estructuración de rutas culturales. Dentro de la geografía del Estado existen ciudades y pueblos que cuentan con un patrimonio cultural de suma importancia, sin embargo, se pueden potenciar sus recursos culturales a fin de conseguir una competitividad turística tanto a nivel nacional como internacional.

Por lo mencionado anteriormente, se puede formular la siguiente hipótesis de trabajo: el fomento y captación del turismo espiritual y cultural en Guanajuato, y sus diversas 
ciudades, como parte de políticas públicas racionales, se fortalecería e impulsaría con una guía cultural impresa para nuevos sectores de mercado, ya que se prestaría un servicio de promoción turística.

Para tal efecto, se efectuó una revisión de la legislación existente sobre el tema y de autores que teorizan sobre el patrimonio cultural, el turismo espiritual.

Basta señalar en este apartado la relevancia que denota el concepto de turismo cultural como actividad detonante del crecimiento económico de las diversas regiones de México, en específico Guanajuato, sus ciudades, poblados y paisajes, los cuales pueden posicionarse precisamente con el fomento de su patrimonio cultural espiritual a través de la guía cultural propuesta, lo que implicaría competir en el mercado nacional e internacional por su oferta turística, la cual puede diversificarse.

En efecto, existen diversos motivos para la realización de viajes turísticos, tales como los culturales espirituales de los que Guanajuato y su entorno son pródigos por su patrimonio cultural, lo que puede darse a conocer a través de rutas culturales que se pueden estructurar mediante un proyecto impreso en la forma de folleto libro. Lo que puede aprovecharse en Guanajuato, y otras ciudades clave, a fin de integrar un circuito cultural turístico, dándolo a conocer a través de una guía cultural o varias guías temáticas que impulsaría el Gobierno estatal.

La ciudad de Guanajuato, por sí sola, cuenta con un paisaje tanto natural como cultural que le ha valido ser Patrimonio Cultural de la Humanidad, lo cual puede apreciarse de forma sistemática con la guía cultural propuesta, en toda su magnificencia arquitectónica expresada en sus templos, plazas, el trazado urbano, en relación a su paisaje natural y a sus tradiciones inmateriales llegando a las culinarias.

En este sentido, una guía cultural impresa en folleto libro formaría parte de la interpretación de la dinámica y estructura de Guanajuato como destino turístico Patrimonio de la Humanidad.

Aspecto $\mathrm{N}^{\circ}$ 3: Puesta en valor turístico del patrimonio, resulta fundamental, una vez reconocidos los valores patrimoniales del destino, la observancia evolutiva de la mirada turística de dicho patrimonio, en el que se deben analizar los productos emergentes exitosos o no y la funcionalidad turística de la ciudad (Lanuza, A., 2012, p. 76). 


\section{Metodología}

La presente investigación tiene como finalidad analizar la relevancia que tendría la implementación de políticas públicas idóneas, a fin de impulsar el turismo cultural espiritual en Guanajuato y sus alrededores, mediante la elaboración y estructuración de una Guía cultural, pretendiendo llegar a un sector demandante de este tipo de turismo, lo que implicaría la oferta del mismo destino mediante esta herramienta, que daría a conocer el patrimonio cultural de Guanajuato configurado por sitios emblemáticos que reflejan una espiritualidad y una tradición religiosa importantes.

El método o la forma de aproximarnos a este problema de investigación fue de carácter cualitativo, mediante técnicas tales como entrevistas en profundidad con expertos del tema, mediante la Observación Participante en toda la topografía cultural espiritual de la ciudad de Guanajuato, así como del análisis de la legislación de la materia para contextualizar el problema de investigación. Se partirá de un marco conceptual relativo al patrimonio cultural, turismo religioso, oferta turística y protección legal del patrimonio cultural.

\section{Cultura y turismo religioso}

En el caso de la cultura religiosa en Guanajuato la fe no se entiende sin la cultura, la fe misma es cultura pues no existe una fe desnuda, una fe como simple religión, aunque puede darse el caso que exista una cultura exenta de religión: la moderna civilización tecnológica. Los Templos de Guanajuato y en otras ciudades como Celaya, San Miguel de Allende y Salvatierra, entre otras, son expresiones de su cultura religiosa, son los lugares y espacios fundamentales en los que se lleva la praxis de la fe, estos edificios sagrados son el orgullo de las ciudades guanajuatenses que cuentan con una serie de monumentos que engalanan su acervo artístico.

El patrimonio cultural de Guanajuato, en cuanto a esta arquitectura sagrada, es el espacio en el que se manifiesta un compromiso fundamental, tanto de la población local como de las autoridades civiles, en el cuidado de dicho patrimonio. 
La mentalidad de la cultura local guanajuatense se reviste de un fuerte arraigo de tradiciones vinculadas a la liturgia católica, con sus procesiones, cofradías, asociaciones religiosas, patronazgos y mayordomías.

La ciudad de Guanajuato tiene una amplia y variada cultura popular que se relaciona frecuentemente con patrones religiosos, dando lugar a un sincretismo cultural muy profundo, sui generis, de raigambre hispana e indígena.

La concepción católica del espacio marcó no solamente la vida cotidiana sino la percepción de la distribución de los espacios y de los objetos en estos espacios en el universo guanajuatense:

En la región de Guanajuato se han conjugado elementos religiosos y antirreligiosos de varios grupos, y en la síntesis de la lucha entre comprensiones, agregados, incomprensiones, intolerancias y tolerancias, contradicciones y concordancias conscientes e inconscientes se entiende e interpreta al mundo más cercano: lo moderno frente a lo conservador, la élite frente al pópulo...el mundo animista de chichimecas y africanos se conjugó con el mundo mágico-religioso mesoamericano y con el mundo fantástico-racional-religioso-mágicocientífico europeo, y, como en muchos otros lados de México, convive lo 'popular' con lo 'culto', lo 'racional' con lo 'mágico', la ‘superstición' con lo 'científico'; el que define con lo definido, lo negado con lo reconocido (Guevara, M. 2001, pp. 84-85).

Desde luego que existe en Guanajuato esa fe hecha cultura así como también la verbena popular a la que es dado el guanajuatense y que también forma de parte de su patrimonio cultural.

El universitario Don Armando Olivares Carrillo en una velada cultural en el Templo de la Compañía sobre el IV centenario de la llegada de la imagen de Nuestra Señora de Guanajuato lo decía de forma literaria:

A veces nos cubrimos de cascabeles locos para pirutear como bufones en las verbenas de las fiestas profanas; a veces urgimos el resplandor de la llama cuando la pasión nos muerde el alma y entonces clamamos como el poeta: corazón mío, yo te sacaré de la sombra y te elevaré como una hostia de fuego...Vivimos hoy una época espantosa de la historia del hombre. Antes, realizadas con las formas de la estética, equilibradas con la armonía de lo justo, saneadas con la limpieza de lo moral, el hombre levantó para habitarlas, las culturas de su historia como arquitecturas espléndidas, mas cimentadas siempre en una irrebatible y gloriosa 
concepción del hombre y su Dios. Como en palacio de limpio mármol, habitó en la cultura socrática de su racionalidad, como en monasterio de egregios perfiles vivió en su fe medioeval; pero hoy, destruidas por las crisis las viejas definiciones del hombre, tal vez en lo futuro sólo podemos asignar a nuestra época triste las rocas bárbaras de una caverna primitiva, primitiva y tecnificada...gracias Señora, porque nos dejaste nacer y vivir en este hueco de la patria de México, que es por tus manos como unidad de plata suspendido entre el prodigio de dos eternidades; como una campana de maravilla desde la torre de nuestra prosperidad antigua colmaba la plata guanajuatense con honor que vuela fabuloso como un surtidor blanco desde el socavón de nuestras minas. (Rangel, M., 1968, pp. 293-294).

Para Frost, E. (2009), refiriéndose a la cultura en general y la cultura mexicana en lo particular, toda "cultura, sin que importe su grado de desarrollo, consta de una técnica y de una concepción del mundo -concretizada en el derecho, la religión, la filosofía, la literatura, el arte - dentro de la cual cobra sentido".

La técnica es el lado utilitario de la labor creadora del hombre, ¿puede compaginarse la cultura técnica en la que nos encontramos con las facultades del hombre tales como la contemplación y la admiración dirigidas a la sabiduría? (de la Calle Vaquero, M., y Hernández, M. G., 2010). El arte sagrado complementa bien este aspecto técnico del hombre.

Los espacios sagrados de Guanajuato, sus Templos, tienen la potencialidad de ser explotados racionalmente como parte de un destino cultural y espiritual turístico, se puede observar y detectar lo que se ha denominado la "espiritualidad como recurso turístico".

La razón misma de esa arquitectura sagrada o Arquitectura de la Fe, como se le ha llamado, tiene una direccionalidad hacia el exterior, al aire libre, patentizándose en los retablos de piedra significativos en Guanajuato:

la sacralización exterior de calles o plazas fronteras por medio de la fachada del templo; en ella se levantó en piedra una maquina quizá más impresionante aún que el interior. El retablo se estructura por calles verticales y cuerpos horizontales, valiéndose de los estípites, de las columnas salomónicas o de los soportes de otro tipo como elementos de separación; la imaginería se distribuye en sus encasamientos no de una manera arbitraria sino siguiendo las 
leyes de simetría y disposiciones horizontales y triangulares, de acuerdo con una tesis dogmático teológicas o de mera exaltación de un santo (Sebastián, S., 1990, p. 61).

Tales elementos se reflejan a plenitud en las principales fachadas de los Templos de Guanajuato, sobre todo en San Diego, la Compañía, Cata (Santuario de Villaseca), Valenciana (San Cayetano), la Basílica de Nuestra Señora de Guanajuato, el patio de la Universidad de Guanajuato en el antiguo Colegio de la Santísima Trinidad de los jesuitas, manifestándose a su vez, el potencial turístico espiritual que poseen; es un recurso cultural que puede ser explotado racionalmente y darlo a conocer a detalle.

Existen retos para potenciar el turismo espiritual en Guanajuato.

El flujo de este turismo espiritual se reduce temporadas, muy significativas en Guanajuato, en enero de cada año, por ejemplo, se pueden llenar de peregrinos los Templos de Guanajuato, sobre todo los cercanos el Monumento a Cristo Rey, en el vecino Silao, donde se reúnen jóvenes provenientes de diversos sitios del país, Guanajuato se convierte sólo en ciudad de paso.

Caso interesante fué la visita papal al Bajío en 2012, la cual resultó en el ámbito económico muy poco significativa por la derrama de 'turistas', en cuanto peregrinaje muy concurrido , pero sin mayor incidencia en la derrama económica dejada por el turismo espiritual.

El turismo, como parte de la política pública a cualquier nivel de gobierno, así como visto como proyecto de negocio por parte de empresarios, es indudablemente, como objeto de estudio, susceptible de ser abordado desde diferentes áreas del conocimiento. Al relacionarse con distintos elementos de los ámbitos económicos, sociales, políticos, medioambientales y culturales, por mencionar algunos, la actividad turística supone un análisis complejo y, desde luego, se hace perentorio realizar diversos enfoques multidisciplinarios para tener un mejor acercamiento sobre este fenómeno (Lanuza, A. R., 2011).

El turismo, como objeto de estudio e investigación presenta diversas vertientes que pueden ser objeto de distintas disciplinas. El turismo religioso, como lo comparten Ruíz Lanuza, A. y Trejoluna O. (2013), es una de las modalidades del turismo espiritual como categoría "contenida en el turismo alternativo, que por la identidad cultural que encierra, genera grandes flujos de visitantes, acentuándose en aquéllas ciudades cerca de centros de 
peregrinaje importantes donde los desplazamientos son motivados por la espiritualidad" (p. 130).

Nos encontramos, por tanto, ante un testimonio vivo en el que se manifiestan las raíces culturales del pueblo guanajuatense, sin olvidar que el significado de este patrimonio es esencialmente religioso, espiritual.

La arquitectura sagrada de Guanajuato tiene esencialmente un valor espiritual, y en segundo término cultural, histórico, pues tiene en sí misma, como lo refieren García M. y de la Calle M. (2013) un "valor originario, propio, preferente y prevalente. El valor cultural, histórico y artístico de un bien sacro, es siempre un valor añadido, un valor secundario y advenedizo que, por muy importante que sea, no puede primar sobre la finalidad primaria" (p. 15), es decir, debe tomarse en cuenta para que están destinados tales espacios sagrados y estar en posibilidad de comprender el significado que tienen para la cultura guanajuatense y su oferta turística en este sentido.

Esta potencialidad turística, todavía no explotada lo suficiente, es susceptible de "cualificar" las visitas turísticas, como lo sostiene Vidaurri, J. (2013), gestionando racional e inteligentemente los recursos culturales de Guanajuato, cuyo consumo de estos bienes culturales sólo se reduce a una mirada romántica de los visitantes a las fachadas de los templos, por otra parte, visitas cada vez menos sistematizadas, como el ejemplo del Templo franciscano de San Diego, que posee una de las fachadas churriguerescas de las más significativas del país dentro de este estilo artístico, lamentablemente extraña para el común de los guanajuatenses, pasando casi desapercibida para el grueso de los visitantes.

\section{El patrimonio cultural de Guanajuato}

Por tanto, como lo sostiene León D. (2011), "los bienes culturales valiosos pueden ser muebles, inmuebles y entes ideales o intangibles que son valiosos o relevantes por su naturaleza histórica, arqueológica y artística o por constituir elementos fundamentales de la cultura e identidad de una sociedad" (p. 18).

Todo lo cual constituye el patrimonio cultural de un pueblo o sociedad susceptible de explotación racional para el turismo espiritual, una verdadera opción de Guanajuato para su oferta hacia México y el mundo. 
En el caso de los Templos católicos en México los rige, de manera enunciativa, la Ley de Asociaciones Religiosas que remite, a su vez, a la Ley General de Bienes Nacionales, la cual regula los inmuebles federales considerados como monumentos arqueológicos, históricos o artísticos conforme a la Ley Federal sobre Monumentos y Zonas Arqueológicos, Artísticos e Históricos.

La misma Ley de Bienes alude a los inmuebles destinados a fines religiosos, los cuales, en este sentido, son destinados a un objeto público (art. 78).

Por su parte, la Ley Federal sobre Monumentos y Zonas Arqueológicos, Artísticos e Históricos establece que:

ARTICULO 33.- Son monumentos artísticos los bienes muebles e inmuebles que revistan valor estético relevante. Para determinar el valor estético relevante de algún bien se atenderá a cualquiera de las siguientes características: representatividad, inserción en determinada corriente estilística, grado de innovación, materiales y técnicas utilizadas y otras análogas.

ARTICULO 36.- Por determinación de esta Ley son monumentos históricos: I.- Los inmuebles construidos en los siglos XVI al XIX, destinados a templos y sus anexos; arzobispados, obispados y casas curales; seminarios, conventos o cualesquiera otros dedicados a la administración, divulgación, enseñanza o práctica de un culto religioso; así como a la educación y a la enseñanza, a fines asistenciales o benéficos; al servicio y ornato públicos y al uso de las autoridades civiles y militares. Los muebles que se encuentren o se hayan encontrado en dichos inmuebles y las obras civiles relevantes de carácter privado realizadas de los siglos XVI al XIX inclusive (1972, http://www.diputados.gob.mx/LeyesBiblio/index.htm, recuperada el 9 de julio de 2016).

En este sentido la legislación federal regula los bienes monumentales que se imponen por su misma relevancia histórica y por ser manifestación cultural del pueblo guanajuatense, en este caso gestionada por la Federación a través de la nueva Secretaría de Cultura y organismos desconcentrados como el Instituto Nacional de Antropología e Historia (INAH). 
Por su parte, el artículo $3^{\circ}$ de la Ley de Turismo para el Estado de Guanajuato y sus Municipios define al turismo cultural, del cual forma parte el espiritual, como

XIV. Turismo Cultural: Son aquellos viajes turísticos que realizan las personas motivados por conocer, comprender y disfrutar el conjunto de rasgos y elementos distintivos, espirituales y materiales, intelectuales y afectivos que caracterizan a una sociedad o a un grupo social de un destino, (2010, www.congresogto.gob.mx/Leyes, recuperada el 9 de julio de 2016).

\section{Resultados y discusión}

Los viajes turísticos espirituales a la región pueden fomentarse dado el patrimonio turístico histórico de Guanajuato, pues en el caso de los Templos de Guanajuato y de otras ciudades, que son parte de su patrimonio cultural, representan y pueden representar, aún más, un atractivo turístico espiritual susceptible de potenciar tales recursos turísticos.

Guanajuato Capital, entre otras ciudades, es claramente una zona de desarrollo turístico sustentable, dadas sus características geográficas, culturales y religiosas.

Por ende, para esta región turística, su desarrollo turístico, debe ser planeado, protegido y ejecutado con políticas públicas racionales que puedan impulsar algunos sectores empresariales.

En el caso de Guanajuato de forma muy enunciativa en el vínculo turismo sólo aparecen enunciados los pueblos mágicos del Estado (Gobierno del Estado de Guanajuato, 2016), informándose sobre estos sitios 'mágicos' del Estado, las zonas arqueológicas y naturales; por su parte el INAH contaba con el vínculo de recorridos culturales teniendo uno destinado a Guanajuato, cuya información cultural era de igual forma muy general, más que detallada, lo que se entiende dada la naturaleza meramente informativa.

Actualmente cuenta el INAH (2016) con un vínculo denominado Paseos Culturales INAH en el que se programan mensualmente in situ diversos recorridos culturales (INAH, 2016). En el sitio web del INAH (2016) se reseñan históricamente los sitios patrimoniales, su arquitectura y hechos relevantes acaecidos en ellos, cuenta el sitio con 50 miniguías cuyo contenido son materiales informativos disponibles para el público en versiones impresas y electrónicas. En el vínculo Guanajuato no existe todavía información alguna. 
Asimismo, en su momento el Ayuntamiento de Guanajuato editó en 2001 la Guía Histórica de Guanajuato de Manuel Sánchez Valle, en la que se hace un recorrido cultural histórico sobre el patrimonio arquitectónico, religioso y cultural de la ciudad de Guanajuato.

Por su parte, de apreciable manufactura, material y fotografías, y dirigida al turismo comercial, se cuenta con la Guía del Estado de Guanajuato de Ediciones Nueva Guía, también de 2001. La literatura especializada sobre patrimonio histórico de Guanajuato se enuncia en el apartado de referencias.

Sin embargo, no existe una guía, para el caso del turismo cultural-espiritual de Guanajuato, apropiada y manejable que reúna características de contenido científico de interés para un sector interesado en el turismo cultural y espiritual de Guanajuato y de otras ciudades del Estado.

Después de una investigación de campo cualitativa, mediante la técnica de entrevistas a profundidad con especialistas universitarios en la materia, emprendida en la ciudad de Guanajuato, y habiéndose revisado el estado de la literatura actual en esta temática y sus avances, y aplicado técnicas como la Observación Participante en la topografía cultural de Guanajuato, se arribó a que actualmente existe una carencia de una guía cultural impresa y a la pertinencia de su elaboración, relativa a Guanajuato y a otras ciudades del Estado o de regiones culturales.

La Guía cultural impresa representaría un producto en el que se presente el patrimonio cultural de Guanajuato, su geografía, historia, la descripción y explicación a profundidad en este documento del arte y tradiciones en la Ciudad, así como de sus rutas junto a otras regiones dependiendo de la temática a desarrollar, formada por un panel de especialistas en el que la interdisciplinariedad se reflejara en el documento, contando con publicidad para su mismo financiamiento. 


\section{Conclusiones}

I. A fin de impulsar y potenciar el turismo espiritual-cultural de la ciudad de Guanajuato, entre otras, la Guía cultural tendría como objetivo dar a conocer a detalle a un sector más especializado o interesado en los acervos espirituales-artísticos de la Ciudad o ciudades del Estado, el patrimonio con el que cuenta Guanajuato.

II. Esta guía cultural sería parte de una política pública que abarca la gobernanza que se manifiesta en la solución de un problema, en este caso, la captación de más turismo en la región, detonando impulsos empresariales en ese sector.

Parte de la estrategia para lograr tales efectos, sería precisamente el marketing que implicaría, por parte del gobierno municipal o estatal, las acciones pertinentes a fin de hacer atractivos los lugares de las ciudades guanajuatenses. Con este marketing se conseguirían nuevos nichos de mercado para el turismo, el cual se beneficiaría con la estructuración de estas guías culturales, esto es, como un producto y servicio en los destinos turísticos para satisfacer algunos sectores interesados en el turismo cultural, promocionándose las riquezas culturales de los destinos para Guanajuato y sus diversas ciudades.

La preservación del patrimonio cultural resulta ser parte de las políticas públicas en turismo, en este sentido la investigación y difusión de la información cultural hecha en forma de guías culturales potenciaría, de forma indirecta, el desarrollo económico de las ciudades guanajuatenses por medio del marketing que tendría como objetivo principal, posicionar los destinos turísticos del estado.

III. Dicho proyecto puede reunir, para su elaboración, especialistas en Historia de la región, historiadores de arte y/o de arquitectura, antropólogos, geógrafos, especialistas en patrimonio cultural en general, de tal manera que, en forma conjunta e interdisciplinaria, se estructure la guía en forma de libro folleto, de buen material y con fotografías de calidad, que permitan al lector hacer un recorrido sistemático de los espacios destinados a este turismo cultural espiritual.

IV. Se ha detectado dentro de los visitantes de la región, en Guanajuato, que al entrar, por ejemplo, a los templos lo hacen a la manera del curioso sólo para tomar fotografías sin mayor incidencia en su formación cultural espiritual.

Las guías responderían a esta situación, con el objetivo de llegar a un turismo cultural, espiritual, que puede encontrar en Guanajuato todo un patrimonio que puede ser tratado de 
forma científica, racional, precisamente a través de libros folletos manejables por el turista y que pueda tener a mano una información más profunda sobre el propio patrimonio cultural que engalana la ciudad.

V. Los templos de Guanajuato, y de otras ciudades del Bajío, junto a sus tradiciones bien pueden tratarse de forma sistemática en estas guías, mismas que propondrían recorridos culturales sacros, por ejemplo, la Semana Santa en el Templo de la Compañía puede explicarse a detalle en la Guía, el significado, los actores, el arte, la literatura. Se puede acompañar con información de la misma tradición y cultura culinaria de la ciudad.

La inquietud sobre este proyecto para ofertar el turismo cultural existe en diversas instancias de la ciudad: Ayuntamiento, Universidad, Gobierno estatal, y la Iglesia, se organizan en sus recintos conferencias sobre arte sacro, se presentan conciertos de música religiosa, se han puesto a la salida de los templos columnas informativas en dos idiomas explicando el edificio respectivo.

VI. Podrían, asimismo, a la manera de las catedrales góticas en Francia, presentar las riquezas del patrimonio artístico guanajuatense en pantallas gigantes tipo IMAX, del que ya se están empezando a realizar, algún 'performance' de iluminación sobre las fachadas de las iglesias más emblemáticas.

VII. Las políticas públicas a nivel Gobierno estatal, relativas al turismo, pueden estructurar guías culturales, las cuales podrían ser un factor más de divulgación cultural a un turismo ávido de experimentar lo espiritual en Guanajuato, su patrimonio puede rebasar tales expectativas, gracias a la investigación llevada a cabo en diversas unidades de observación, tales como los Templos de Guanajuato.

En efecto, las Guías propuestas pueden presentar y estructurar una o varias rutas culturales pudiendo contribuir a ofertar, como parte de las políticas públicas en la materia de atención al turismo espiritual o cultural, toda la riqueza patrimonial cultural todavía poco valorada y apreciada en las visitas a Guanajuato y otras ciudades, presentando itinerarios culturales potenciales, rutas culturales sacras, rutas de los conventos en Guanajuato, rutas culinarias o gastronómicas, rutas de las presas en Guanajuato, entre otras.

VIII. Dentro de las políticas culturales del Ayuntamiento o del Gobierno estatal en Guanajuato, se hace pertinente hacer las correcciones que se necesitan y que se tome 
conciencia de ello por parte de los técnicos y políticos, a veces tan poco sensibles a los valores históricos que deberían esforzarse en tutelar y conservar.

En México existe el prurito de estar legislando al mayoreo, como si fuera la varita mágica que convirtiera al país en la realidad que todos quisiéramos, no por hacer una ley de turismo se va a traer el turismo, muchas de las leyes son para regular la burocracia, en este caso, del turismo.

Se requiere en Guanajuato una mayor conciencia de hacer un turismo cultural espiritual, que bien puede ser ofertado, un comienzo sería este proyecto de una Guía cultural, incluso financiada, por las empresas que pueden ser beneficiadas por el turismo. Guanajuato se lo merece. 


\section{Bibliografía}

Alcocer, A. (1988). Bienes inmuebles del patrimonio histórico y artístico de la Universidad de Guanajuato en la capital del estado y la pintura en el Colegio de Guanajuato, en el siglo XIX (pp. 173-180). En Guanajuato: la cultura en el tiempo.México: El Colegio del Bajío.

Almanza, R. (2011). Guanajuato y San Miguel de Allende: dos ciudades patrimoniales del estado de Guanajuato (pp. 51-88). En Estudios sobre el patrimonio de Guanajuato. Guanajuato: Universidad de Guanajuato.

Arellano, I. (1988). La vida humilde de los dieguinos (pp. 45-52). En Guanajuato: la cultura en el tiempo.México: El Colegio del Bajío.

Ayala, Javier. (2010). El Diablo en Nueva España. México: Universidad de Guanajuato.

Belmonte, R. A., 2009, Ciudades patrimonio de la humanidad: ¿una significación valorada turísticamente?). Recuperado el 12 de Agosto de 2016 de http://148.228.173.140/topofiliaNew/assets/coloquio09arroyo.pdf

Blanco, M., Parra, A. y Ruíz, E. (200). Breve historia de Guanajuato, México: FCE.

Brading, D. (2009). Origen de la grandeza de Guanajuato (pp. 29-88). En Renovada Grandeza de Guanajuato. México: Artes de México.

Covarrubias, S. (2000). Arquitectura. En Teatro Juárez. (pp. 55-79). Guanajuato: Ediciones La Rana.

Covarrubias, S. (2009). Antiguo crisol de metales (pp. 21-28). En Renovada Grandeza de Guanajuato. México: Artes de México.

De la Calle Vaquero, M., \& Hernández, M. G. (2010). Actuaciones para el desarrollo del turismo cultural en las ciudades Patrimonio de la Humanidad de España. En Dinámicas funcionales del turismo y sus impactos en las ciudades Patrimonio de la Humanidad: estudios comparados entre México y España (pp. 37-54). Universidad de Guanajuato).

Durand, G. (2012). Las estructuras antropológicas del imaginario. México: FCE.

Elizondo, R., 2003). Guía Muestra para la Identificación y Diseño de Productos de Turismo Cultural de las Ciudades mexicanas Patrimonio de la Humanidad: Guanajuato, Morelia, Querétaro y Zacatecas. 
Frost, E. (2009). Las categorías de la cultura mexicana. México: FCE.

García, J. (2014), Periódico AM, Recuperado el 12 de Agosto de 2016 de http://www.am.com.mx/leon/local/invierten-93-millones-en-templos-166682.html

García M. y de la Calle M. (2013). Las catedrales españolas en dimensión turística. Diversidad de visitantes e incipientes problemas de sobrecarga. En La espiritualidad como recurso turístico: propuestas, experiencias y aproximaciones. (pp. 13-31). Guanajuato: Universidad de Guanajuato. Recuperado el 03 de Junio de 2016 de, http://issuu.com/rigamu73/docs/libro_agustin1issu_galeras.

Geertz, C. (2006). La interpretación de las culturas. Barcelona: Gedisa.

Gobierno del Estado de Guanajuato, 2016. Recuperado el 12 de Agosto de 2016 de (http://guanajuato.gob.mx/5-pueblos-magicos.php)

Gómez, J. G. G., \& Rocha, M. I. M. (2015). Turismo y Patrimonio. Caso: Ciudad de Guanajuato. JÓVENES EN LA CIENCIA, 1(2), 936-940).

González, P. (2000). Geografía Local del Estado de Guanajuato. Guanajuato: Ediciones La Rana.

Guevara, M. (2001). Guanajuato Diverso: Sabores y sinsabores de su ser mestizo (Siglos XVI a XVII). Guanajuato: Ediciones la Rana.

Guevara, M. (2011). Conservación del patrimonio histórico minero. Guanajuato en el siglo XVIII: ciudad patrimonio (pp. 89-124). En Estudios sobre el patrimonio de Guanajuato. Guanajuato: Universidad de Guanajuato.

Hernández, R., Fernández, C. y Baptista, P. (2010), Metodología de la Investigación, México: Mc Graw Hill/Interamericana.

INAH, (2016), Paseos culturales, Recuperado el 12 de Agosto de 2016 de http://www.inah.gob.mx/es/inah/5236-paseos-culturales-inah)

Miniguías, 2016, Recuperado el 12 de Agosto de 2016 de (http://www.inah.gob.mx/es/inah/5085-miniguias)

Lara, J. (1999). Historias urbanas de la ciudad de Guanajuato. Guanajuato: Presidencia Municipal de Guanajuato.

León, D. (2008). Compilación Histórica de la Universidad de Guanajuato. Guanajuato: Universidad de Guanajuato. Centro de Investigaciones Humanísticas. 
León, D. (2011). Patrimonio cultural nacional: comentarios sobre su legislación (pp. 1350). En Estudios sobre el patrimonio de Guanajuato. Guanajuato: Universidad de Guanajuato.

López, M. R. S., 2000. La rehabilitación de los centros históricos en México: un estado de la cuestión. México DF.

Martínez, C. (2001). Los sentimientos de la región. Del viejo centralismo a la nueva pluralidad.México: INHERM-Océano.

Moreno, M. (1989). Guanajuato: Cien años de Historia (1867-1967). Guanajuato: Gobierno del Estado de Guanajuato.

Olmos, G. (2009). Un trabajo en el tiempo. Entrevista con los Consejeros de Guanajuato Patrimonio de la Humanidad, A.C. (pp. 89-112). En Renovada Grandeza de Guanajuato.México: Artes de México.

Olmos, G. (2009). La Restauración, una aventura silenciosa. Entrevista con las Restauradoras de Guanajuato Patrimonio de la Humanidad, A.C. (pp. 113-133). En Renovada Grandeza de Guanajuato. México: Artes de México.

Pérez, S. (1988). Pensamiento educativo que conforma nuestra identidad. (pp. 311-328). En Guanajuato: evolución social y política. México: El Colegio del Bajío.

Piñón, E. (1994). El Oratorio de San Felipe Neri en Guanajuato (pp. 44-117). En El Oratorio filipense en Guanajuato 200 años y los precursores jesuitas. México: Ediciones Estudio 54.

Puy-Alquiza, M. J., Miranda-Avilés, R., Salazar-Hernández, C., \& Vega-González, M. 2013). Characterization petrophysical of the Losero Formation in the historical architecture of the Guanajuato city, Mexico. Ingeniería Investigación $y$ Tecnología, 14(2)

Rangel, M. (1968). En IV Centenario de Nuestra Señora de Guanajuato. León: Manuel Quesada Brandi Editor.

Rodríguez, J. (1988). La Universidad de Guanajuato en su origen (pp. 71-98). En Guanajuato: la cultura en el tiempo.México: El Colegio del Bajío.

Ruíz Lanuza, A. (2012). Guanajuato (México): dinámica y estructura de un destino turístico patrimonio de la humanidad (Doctoral dissertation). Recuperado el 12 de Agosto de 2016 de http://eprints.ucm.es/14661/1/T33630.pdf 
Ruíz Lanuza, A. y Trejoluna, O. (2013). La incidencia turística en los eventos religiosos excepcionales. Caso: Visita del Estado Vaticano a Guanajuato. En La espiritualidad como recurso turístico: propuestas, experiencias y aproximaciones. (pp. 124-144). Guanajuato: Universidad de Guanajuato. Recuperado el 03 de Junio de 2013 de, http://issuu.com/rigamu73/docs/libro_agustin1issu_galeras.

Salazar, J. (2000). Historia. En Teatro Juárez (pp. 15-54). Guanajuato: Ediciones La Rana.

Sánchez, A. (1999). La guerra cristera en Guanajuato. Guanajuato: Ediciones La Rana.

Sánchez, M. (2001). Guía Histórica de Guanajuato. Guanajuato: Presidencia Municipal de Guanajuato.

Sánchez, M. (2005). Los Minerales Marfil y Valenciana. Guía Histórica de Guanajuato. Guanajuato: Ediciones La Rana.

Santiago, S. (1990). El Barroco Iberoamericano, Mensaje iconográfico. Madrid: Ediciones Encuentro.

Serrano, L. (2001). El Templo parroquial de Santa Fe. Programas Iconográficos del siglo XVIII de Guanajuato. Guanajuato: Ediciones La Rana.

Serrano, L. (2002). San Diego. El Templo conventual de San Pedro de Alcántara. Guanajuato: Ediciones La Rana.

Serrano, L. (2003). Valenciana. El Edificio y sus programas Iconográficos. Guanajuato: Ediciones La Rana.

Silva, J. (2004). El Templo Agustino de San Juan de Sahagún en Salamanca. Apoteosis Barroca. Guanajuato: Ediciones La Rana.

Valencia, G. (1998). Guanajuato: Sociedad, Economía, política y cultura.México: UNAM.

Vidaurri, J. (2013). El patrimonio religioso de la ciudad de Guanajuato como atractivo turístico. En La espiritualidad como recurso turístico: propuestas, experiencias y aproximaciones. (pp. 57-77). Guanajuato: Universidad de Guanajuato. Recuperado el de Junio de 2013 de, http://issuu.com/rigamu73/docs/libro_agustin1issu_galeras.

Woitrin, E. (2011). El paisaje como patrimonio y el hito paisajístico de la Bufa en la ciudad de Guanajuato (pp. 289-314). En Estudios sobre el patrimonio de Guanajuato. Guanajuato: Universidad de Guanajuato. 